\title{
UTILIZATION OF Dendrobium crumenatum AS ANTI-CORROSION ADDITIVE FOR MILD STEEL IN DIFFERNT SEAWATER VELOCITIES
}

\author{
NAZATUL TARMIZI ${ }^{2}$, HUI SHIN YEN ${ }^{1}$, NABILAH ISMAIL ${ }^{* 1}$, WAN NORSANI WAN NIK ${ }^{2}$, \\ NUR KHAIRUNNISA NAZRI ${ }^{1}$ AND SITI AISYAH MOHAMED DIAH ${ }^{1}$
}

${ }^{1}$ Faculty of Science and Marine Environment, ${ }^{2}$ Faculty of Ocean Engineering Technology and Informatics, Universiti Malaysia Terengganu, 21030 Kuala Nerus, Terengganu, Malaysia.

*Corresponding author: nabilah.i@umt.edu.my

Submitted final draft: 28 November 2019 Accepted: 15 December 2019

http://doi.org/10.46754/jssm.2020.07.004

\begin{abstract}
Recently, the development of green corrosion inhibitors and green inhibition strategies has become highly demanded due to the increased demand for green chemistry in the area of science and technology. This present research is about Dendrobium crumenatum (D. crumenatum), also known as pigeon orchid; a green additive to protect the mild steel coupon from corrosive effect in different seawater velocities. This study was held within 35 days of immersion with data interval of 7 days. Secondary metabolites in $D$. crumenatum play an important role in $D$. crumenatum as green additives. The chemical constituents of the D. crumenatum were investigated through Fourier-transform infrared spectroscopy (FTIR). The corrosion inhibition efficiency of $D$. crumenatum was analyzed through electrochemical impedance spectroscopy (EIS), scanning electron microscopy (SEM) and Optical Microscope. To investigate the seawater velocity as disturbance factor to the corrosion inhibition, different seawater velocities ranging from $0 \mathrm{~m} / \mathrm{s}, 0.074 \mathrm{~m} / \mathrm{s}$, $0.094 \mathrm{~m} / \mathrm{s}, 0.114 \mathrm{~m} / \mathrm{s}$ respectively were utilized using aerator. The rate of corrosion was tested via weight loss and potentiodynamic polarization. The present work showed that D. crumenatum has a good performance as green additive in minimizing corrosion effect on mild steel via the morphological analysis. Meanwhile, based on the result, highest velocities at $0.114 \mathrm{~m} / \mathrm{s}$ had caused highest corrosion rate $0.19 \mathrm{~mm} /$ year after Day 35 which indicate that the oxidation process vigorously occurred at high velocity.
\end{abstract}

Keywords: Dendrobium crumenatum, corrosion rate, green additive, seawater, sustainable.

\section{Introduction}

Mild steel is known as a common metal used in marine operations. It is inexpensive, has a good strength, can be bent and welded easily as well as it has high manufacturing value. Unfortunately, mild steel can easily corrode when exposed to the corrosive environment since it has low corrosion resistance (Ebenso et al., 2008). Examples of steel applications in marine industries are mostly for shipbuilding such as ship hull, strips, marine pipelines, flat bars and cargo tanks. This is a major issue to overcome by the educational and industrial sectors as it causes enormous economic losses all over the world (Alibakhshi et al., 2018).

In the marine industry, corrosion has become the main problem where it can cause serious effects in terms of high maintenance cost, safety and disturbance in industrial production. Corrosion can cause failure to metallic structure in the industry, thus increasing monetary problems, for instance, the marine industry in the United States has reported $\$ 785$ million out of $\$ 810$ million that was used for maintaining and repairing while $\$ 1.12$ billion was spent on new constructions (De Baere et al., 2013). Seawater is an important medium for marine industries in shipping, offshore oil and gas production, seawater cooling system and power plants (Ahmad, 2014). Naturally, corrosion in the maritime industry occurs when a metal is in contact with seawater. Corrosion is a metal deteriorating process when exposed to water, humid air, acids and salts (Siegwart, 2006). However, the velocity due to flowing seawater can lead to erosion-corrosion.

Erosion corrosion is the rate of corrosion attack due to relative motion of corrosive fluid 
on metal surface. The higher the velocity of seawater, the higher the corrosion rate (Fredj et al., 2012). Current techniques to overcome this problem evolve around multiple inorganic additives, which contain heavy metal and high level of toxicity that threaten aquatic life. Additive is a special substance that gives ahuge impact on paints even in a small amount. The use of additive, given the right time, order and proportion can help improve the coating system. It can help in improving the form of appearance paint durability or flow of the paints (Maria et $a l .$, 2019).Thus, green corrosion additive has been proposed to minimize corrosion in the maritime industry (Ramezanzadeh et al., 2018).

D. crumenatum is a scientific name of pigeon orchid, which is a member of Orchidaceae family. Pigeon orchid is a type of common plant in Malaysia that can be also found in India, the Philippines, China and Indonesia. The beautiful appearance of its white colour is similar to a bunch of doves that are flying, which contributed to its name. Despite its fragrance and attractive appearance, the chemical compounds namely alkaloid, polyphenol and flavonoids contained in this orchid put it into a lot of advantages (Verma et al., 2018). This kind of orchid becomes very important to the Chinese traditional herbs as it is very effective in healing some diseases especially ear infection (Yan et al., 2015). Besides, it has been proved that $D$. crumenatum has antimicrobial activities against selected pathogenic bacteria (Sandrasagaran et al., 2015). D. crumenatum is very economical, easily affordable since it grows evenly and can be planted on cork or tree fern rootstock. Moreover, the compound contained in this orchid makes it environmentally friendly and effective to minimise corrosion activity against mild steel. Therefore, this study attempts to utilise green anti-corrosion additive using $D$. crumenatum stem rather than synthetic additive, as the former is environmentally friendly besides reducing the corrosion rate against various seawater velocities.

\section{Materials and Methods}

\section{Materials}

The metal used was mild steel grade JR235 with dimension of $25 \mathrm{~mm} \times 25 \mathrm{~mm} \times 3 \mathrm{~mm}$ and was prepared in a quantity of 64 pieces. Each of the mild steel was drilled to make a $3 \mathrm{~mm}$ hole using a milling machine to hang it for the immersion test. The cleaning process started by polishing the mild steel surface using three different grades of sandpaper, which were 180 $\mathrm{cw}, 320 \mathrm{cw}$, and $600 \mathrm{cw}$ to produce a smooth surface. The necessity of polishing the SS316L was to ensure that the layer of carbon oxide is removed so that it will not interfere with future procedure (Ikhmal et al., 2018). Then, mild steel was degreased individually with ethanol and rinsed with distilled water (Niu et al., 2017). Finally, the mild steel was allowed to dry and stored at room temperature.

\section{Preparation of Pigeon Orchid Extract}

Firstly, the sample of this orchid collected from a local farm was cleaned with tap water and cut into short pieces. Then, it was dried into the oven for $50{ }^{\circ} \mathrm{C}$ for 72 hours to ensure a complete dryness. The dried sample was ground using a Kensington brand GTM-8803 model blender to produce fine powder to maximise the extraction process. The sample was soaked in the acetone solvent AR for 3 days to extract the bioactive compounds. It was filtered using Buchner funnel for three times to ensure no insoluble particles were left inside the solvent. The filtered extract was then ready to be reduced in volume by using a rotary evaporator. Hence, the crude extract was obtained.

\section{Apparatus Setup}

The naked mild steel coupon was weighed using an analytical balance to get the initial weight before the experiment started. Each coupon was coated with a mixture of black oxide primer, 10 $\mathrm{mL}$ of $20 \%$ pigeon orchid extract and $80 \%$ epoxy resin. After coating, the coupons were left to dry for 1 day at room temperature. The coupons were then weighed again to obtain the initial weight after coating. Four aquaria containing 3 
$\mathrm{L}$ of seawater were prepared for the immersion test and each aquarium was provided with different velocities from $0 \mathrm{~m} / \mathrm{s}, 0.074 \mathrm{~m} / \mathrm{s}, 0.094$ $\mathrm{m} / \mathrm{s}$ and $0.114 \mathrm{~m} / \mathrm{s}$. Four different aerators were used to produce different velocities. Sixteen coated mild steel coupons were immersed into each aquarium for 35 days.

The mild steel coupons were taken out every 7 days for data measurement. Before the data was taken, the coupons were dried at room temperature to ensure that the moisture was completely removed, hence preventing measurement error. Three assessments were used in analysing the mild steel coupons namely weight loss analysis, morphological analysis using optical microscope and Scanning Electron Microscope (SEM) and Electrochemical Impedance Spectroscopy (EIS) technique.

\section{Results and Discussion}

\section{FTIR of Orchid Extract}

Fourier transform infrared (FTIR) was used to obtain infrared spectra of organic and inorganic materials by measuring the transmittance on the sample materials against its wavenumber (Bakri \& Jayamani, 2016). The Thermo Nicolet Avatar 380 FTIR result (Figure 1) showed a high change in magnitude of the molecule that produced a high intensity of the band. The presence of alcohol, carboxylic acid and amine and imine composition in pigeon orchid's stem was illustrated in that spectrum.

This shows that the pigeon orchid stem contains oxygen, sulfur and nitrogen atoms, which are present in a heterocyclic structure that is able to resist corrosion due to multiple bonds (Abdulla et al., 2009). The bonds stretching occurred by $1375.25 \mathrm{~cm}^{-1}, 2729.27 \mathrm{~cm}^{-1}, 2669.48 \mathrm{~cm}^{-1}$ and $2933.37 \mathrm{~cm}^{-1}$ consisting of $\mathrm{O}, \mathrm{H}$ and $\mathrm{N}$ atoms with a medium and strong signal appearance. The signal was present by $1676.14 \mathrm{~cm}^{-1}$ comprising double bond $\mathrm{C}$ and $\mathrm{N}$ with medium signal appearance.

\section{Weight Loss Analysis}

Weight loss is a traditional and simple method to observe corrosion according to ASTM G31-72 (Arockiasamy et al., 2014). The initial and final weights of metals were evaluated. The results showed that the corrosion rate decreased with increasing flow rate of seawater. In this study, the weight loss was minimal as the flow rate of seawater and immersion time increased, which clearly suggests the inhibition efficiency of $D$. crumenatum.

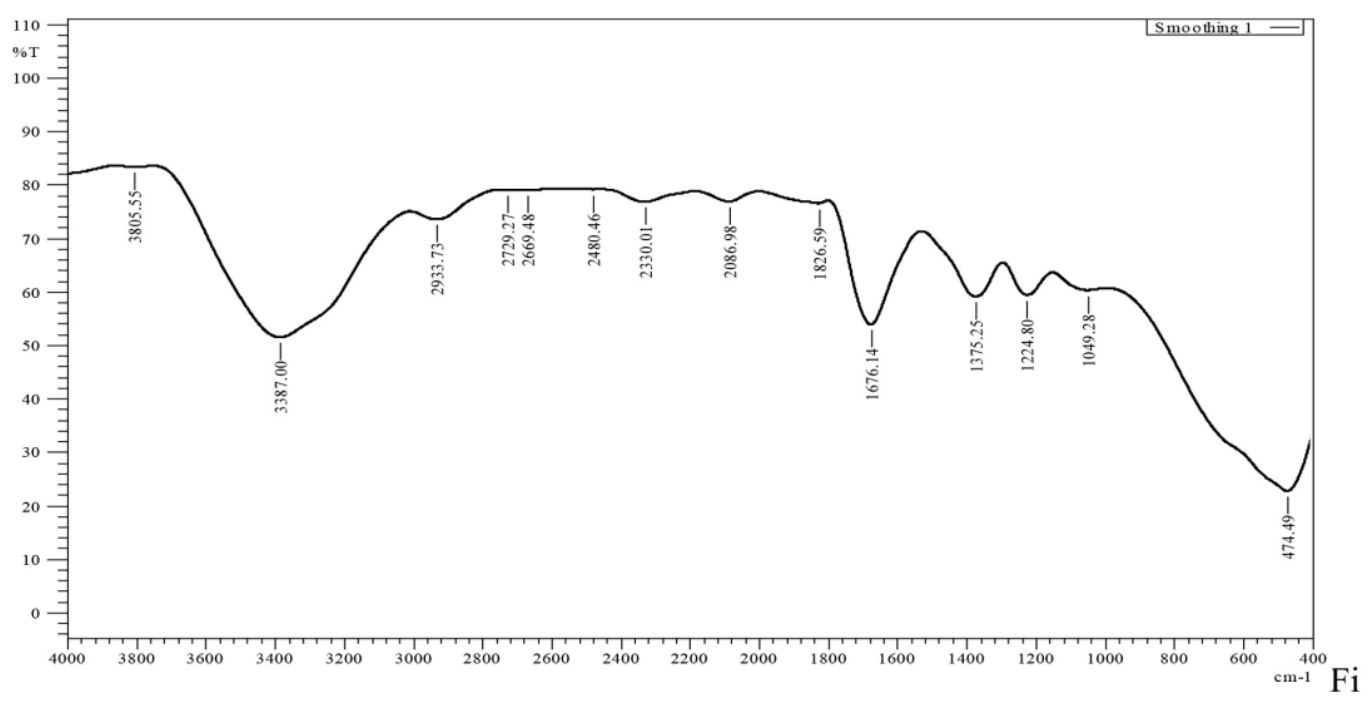

Figure 1: FTIR spectrum pigeon orchid extract 
The weight loss percentage against the period of immersion was plotted as in Figure 2. The rate of corrosion was manually calculated and the data was plotted on a table. The percentage of weight loss and corrosion rate was calculated using the formula below:

Where,

$$
W_{L}(\%)=-W_{i}-W_{f} \times 100 \%
$$

$W_{L}$ - weight loss

$W_{i}$ - weight initial

$W_{f}-$ weight final

In Figure 2, the seawater with a flow rate of $0.094 \mathrm{~m} / \mathrm{s}$ has the highest weight loss percentage. This proved that the high seawater velocity caused an increase in weight loss percentage as the shear stress at high flow velocity increases, causing more oxygen to be delivered to the electrode surface (Li et al.,
2017). Thus, the passivation of metals was due to the oxygen participated in anodic passivation reaction. Meanwhile, the weight loss started to decrease when the velocity increased to 0.114 $\mathrm{m} / \mathrm{s}$, which might be due to the protective coating on the mild steel that started to crack and peeled off from the shear stress (Abadias et al., 2018). Furthermore, the graph shows weight loss percentage values that did not exceed $9 \%$, thus indicating the efficiency of pigeon orchid as a corrosion inhibitor.

Figure 3 shows the comparison between coated and uncoated weight loss percentage in static seawater flow. The uncoated mild steel has higher percentage of weight loss compared to coated mild steel with $20 \%$ of additive. This proves that the addition of additive in coating paint reduces the per cent of weight loss hence reduce the oxidation on mild steel surface.

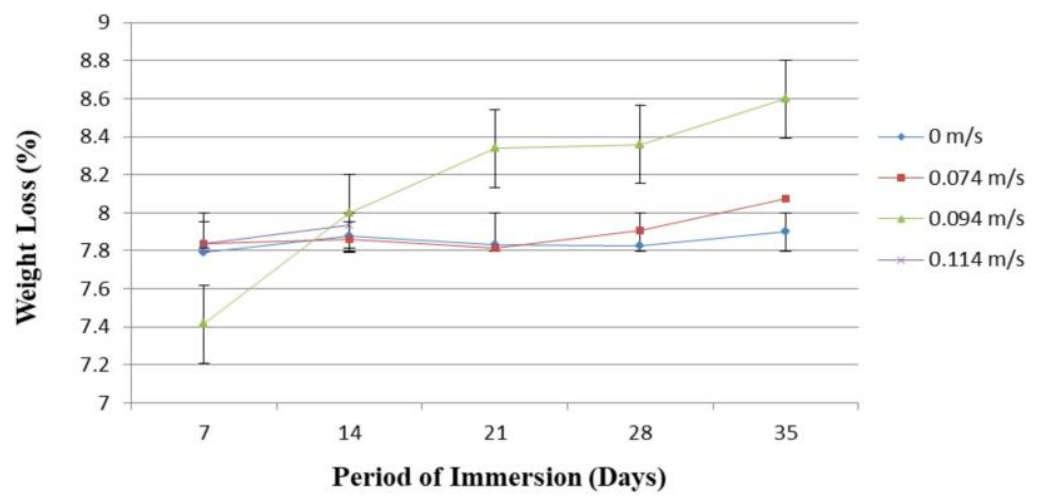

Figure 2: Weight loss percentage of coated mild steel in different seawater velocities

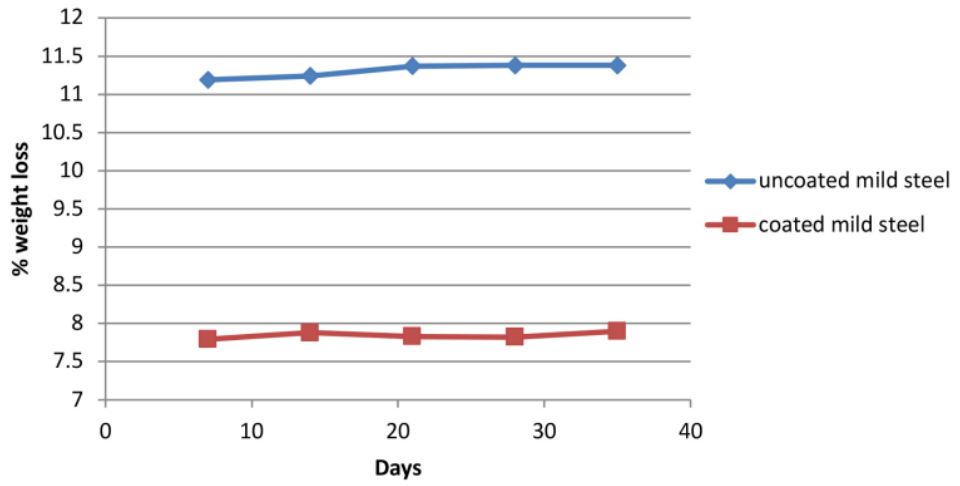

Figure 3: Percentage weight loss of coated and uncoated mild steel in static seawater for 35- day interval 
Table 1 illustrates the result of the corrosion rate for coated mild steel with $20 \%$ additive. The corrosion rate increased along with increasing seawater velocities. According to Li (2017), the influence of corrosion rate due to flow velocity indicates two effects which are mass transfer and surface shear stress effects. These can lead to flow-induced corrosion. The data from the table shows that aquarium with $0.114 \mathrm{~m} / \mathrm{s}$ velocity has the highest corrosion rate, whereas that with 0 $\mathrm{m} / \mathrm{s}$ has the lowest corrosion rate. The corrosion rate decreased over immersion time due to the presence of an inhibitor molecule from $D$. crumenatum to form a complex and diminish the solubility of the surface layer, thus improving the inhibition performance.

\section{Corrosion rate (Equation 2)}

Corrosion rate $(\mathrm{mm} /$ year $)=\frac{33650 \times \text { weight loss }}{D A T}$

Where, $D$ - metal density $\left(\mathrm{g} / \mathrm{cm}^{3}\right)$

$A$ - coupon area $\left(\mathrm{in}^{2}\right)$

$T$ - time (days)

\section{Electrochemical Impedance Spectroscopy (EIS)}

EIS was carried out using AUTO LAB PGSTAT302N controlled by software NOVA 10.1 with parameter frequency range of 100 $\mathrm{kHz}$ to $10 \mathrm{kHz}$. Electrochemical spectroscopy was done for $0 \mathrm{~m} / \mathrm{s}, 0.074 \mathrm{~m} / \mathrm{s}, 0.094 \mathrm{~m} / \mathrm{s}$ and $0.114 \mathrm{~m} / \mathrm{s}$ in day 7 . The result obtained is as illustrated in the impedance diagram (Nyquist plot) and potentiodynamic polarisation table. In this experiment, EIS was used to obtain the resistance transfer and rate of corrosion on mild steel. The data on the $\mathrm{x}$-axis $\left(\mathrm{Z}_{\mathrm{re}}\right)$ indicates real impedance while that iny-axis $\left(Z_{\text {im }}\right)$ indicates imaginary impedance.

From Figure 4, Nyquist plot indicated the strength of the inhibitive film (Satapathy et al., 2009). It shows that the diameter of capacitive semicircle for $20 \%$ was larger than $0 \%$. Increasing diameter indicated increasing potential resistance received by the mild steel, which led to the increased inhibitor efficiency. Since the impedance value of $20 \%$ additives was higher than $0 \%$, the inhibitor efficiency can be assumed to be better in $20 \%$ additive.

Table 1: Corrosion rate of coated mild steel in 35 - day interval

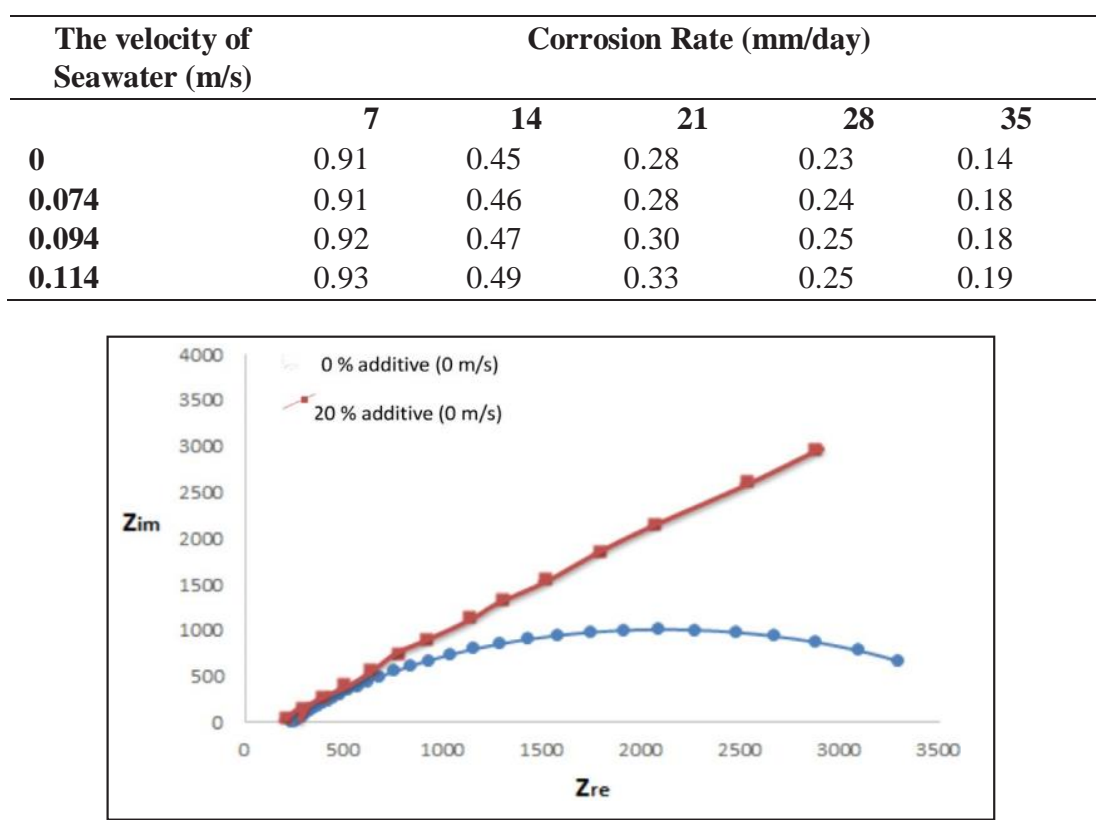

Figure 4: Nyquist plot for inhibition efficiency between mild steel with $0 \%$ and $20 \%$ additive in static water flow 
In Figure 5, the arc curve with $0 \mathrm{~m} / \mathrm{s}$ showed that it was steeper than the other curve. It showed that the resistance transfer was highest at $0 \mathrm{~m} / \mathrm{s}$, followed by $0.074 \mathrm{~m} / \mathrm{s}$, $0.094 \mathrm{~m} / \mathrm{s}$ and $0.114 \mathrm{~m} / \mathrm{s}$. The higher resistance transfer suggested that the mild steel coupon was not heavily affected by different velocities. Meanwhile, the less steep the curve indicated that the mild steel coupon receives less amount of resistance as it is impacted by flow-induced corrosion. When the coupon was impacted by velocities of seawater, the impedance value became lower, thus reducing the ability of inhibitor. The graph below shows the comparison of inhibition efficiency between $20 \%$ additive and $0 \%$ additive for $0 \mathrm{~m} / \mathrm{s}$ velocity on Day 7 .
The data in Table 2 was used to obtain the rate of corrosion from different seawater velocities. From the Table, $b$ stands for an anodic reaction that releases electron into the metal surface while $b_{c}$ indicates a cathodic reaction that receives electron transfer in the metal surface. $E_{\text {corr }}$ value represents the corrosion potential while $\mathrm{I}_{\text {corr }}$ indicates corrosion current density. The $\mathrm{E}_{\text {corr }}$ value will become less negative with the increase of velocity indicating a corrosion potential increase (Lebrini et al., 2011). Increasing velocity caused reduced polarisation resistance, increased $\mathrm{I}_{\text {corr }}$, increased $\mathrm{E}_{\text {corr }}$ and increased corrosion rate, hence reducing the thickness of the paint. However, the corrosion rate value did not exceed 0.9 $\mathrm{mm} /$ year. This means that the pigeon orchid

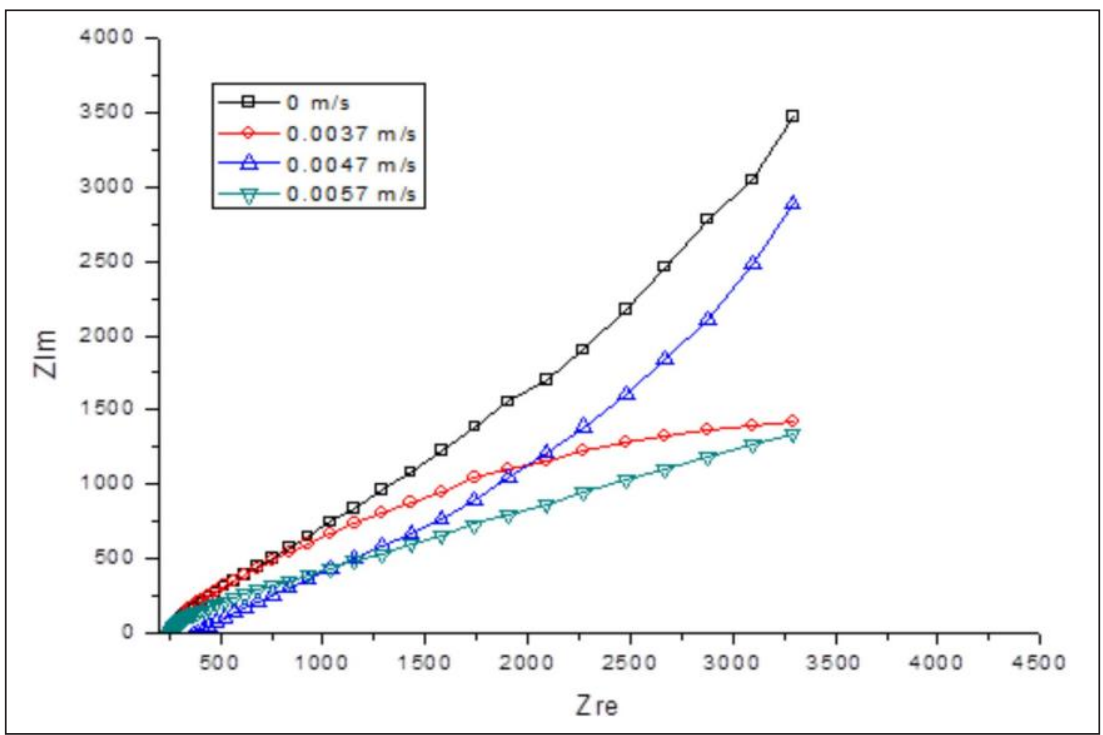

Figure 5: Nyquist plot for mild steel coated with $20 \%$ of additive in different seawater velocities

Table 2: Potentiodydamic polarisation parameters

\begin{tabular}{cccccc}
\hline $\begin{array}{c}\text { Seawater } \\
\text { Velocity } \\
(\mathbf{m} / \mathbf{s})\end{array}$ & $\mathbf{b}_{\mathbf{a}}(\mathbf{V} / \mathbf{d e c})$ & $\mathbf{b}_{\mathbf{c}}(\mathbf{V} / \mathbf{d e c})$ & $\mathbf{- E}_{\text {corr }}$, Calc $(\mathbf{V})$ & $\mathbf{I}_{\text {corr }}(\mathbf{A})$ & $\begin{array}{c}\text { Corrosion rate }(\mathbf{m m} / \\
\text { year })\end{array}$ \\
\hline 0 & 0.489 & 1.067 & 0.650 & $4.08 \mathrm{E}-05$ & 0.47 \\
0.074 & 0.558 & 1.155 & 0.664 & $4.40 \mathrm{E}-05$ & 0.51 \\
0.094 & 0.459 & 0.994 & 0.677 & $5.55 \mathrm{E}-05$ & 0.65 \\
0.114 & 0.639 & 1.577 & 0.715 & $7.28 \mathrm{E}-05$ & 0.85 \\
\hline
\end{tabular}


additives acted actively as corrosion control in this system.

\section{Optical Microscope}

Optical Microscope is a light microscope that uses visible light to magnify images of small objects. In this study, the microscope optic was used to observe the formation of corrosion products on the mild steel surface after being coated with paint containing $20 \%$ additive. Results were taken for $0 \mathrm{~m} / \mathrm{s}, 0.074 \mathrm{~m} / \mathrm{s}, 0.094$ $\mathrm{m} / \mathrm{s}$ and $0.114 \mathrm{~m} / \mathrm{s}$ and the comparison was done between Days 7, 21 and 35.

As shown in Table 3, the highest corrosion product was at $0.114 \mathrm{~m} / \mathrm{s}$ while $0 \mathrm{~m} / \mathrm{s}$ produced less corrosion. This was because the influence of high velocities encouraged high production of a depolarisation agent $\mathrm{H}_{2} \mathrm{CO}_{3}$, thus increasing $\mathrm{H}^{+}$(Niu et. al., 2017). Moreover, the increase in velocity leads to high movement of oxygen to the surface and speeding the oxygen reduction reaction (Fredjet al., 2012), hence inducing corrosion.

\section{Scanning Electron Microscope}

SEM is an electron microscope that produces an image of a sample by scanning samples with focused beam using model JSM-6390LA. It is also used to observe the surface topography and composition of a sample. This current study used SEM to view the morphological surface on mild steel coupon whether or not there were corrosion products or paint failure. The morphological results showed the comparison between uncoated and coated mild steels with additive. The uncoated mild steel after immersion can be seen in Figure 6. For the comparison, the mild steel surface with additive was still protected even though in Figure 7 (a) it showed some corrosion products on the coupon surfaces. Meanwhile, in the uncoated mild steel that was immersed as shown in Figure 5 (b) and (c), the coupon was seen attacked by corrosion.

Figure 5 (c) shows chalking failure on the mild steel surface. Chalking failure occurs due to the mixture used for coating. In this case, the chalking failure arose due to the epoxy resin contained in the coating mixture (Munger, 2014). Even though there was a chalking failure, the mild steel surface was still protected; however, the failure induced colour change and dullness of coating (Munger, 2014).

Table 3: Corrosion images on mild steel surface under optical microscope

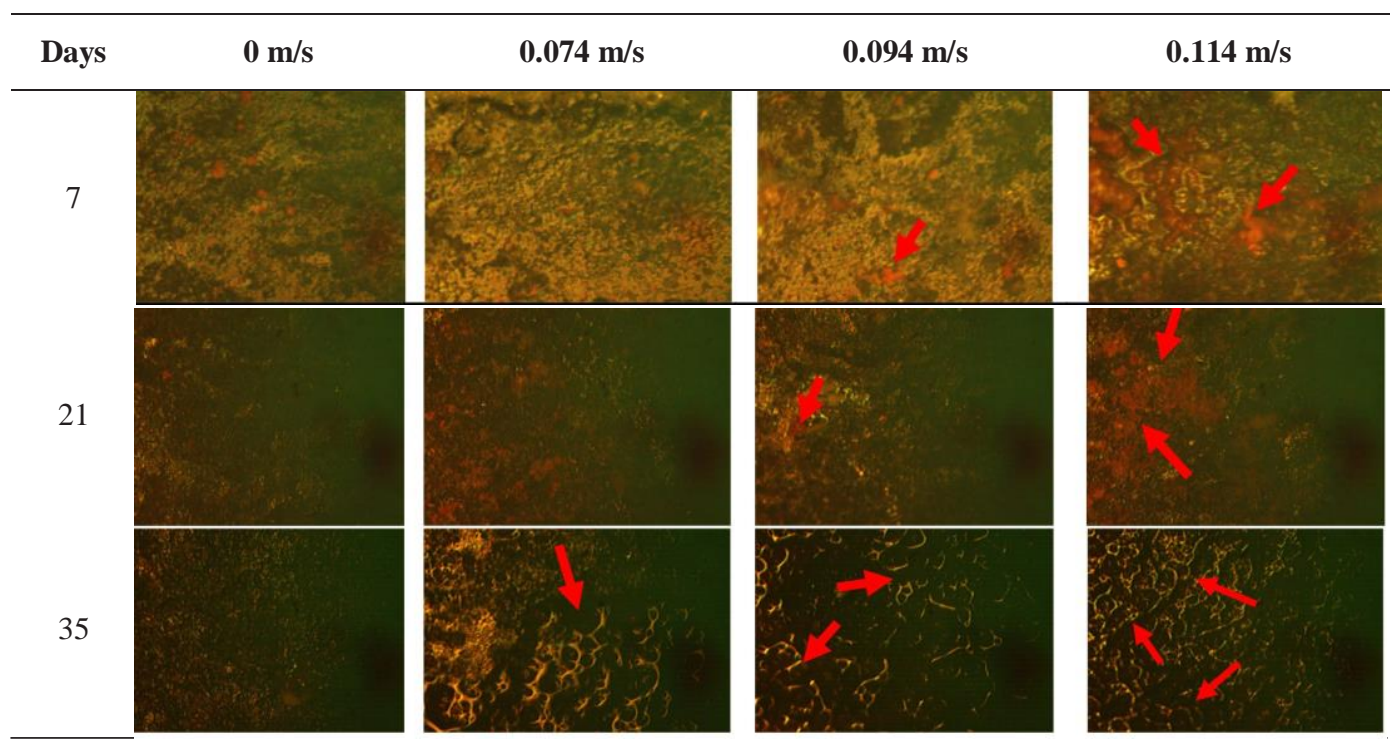




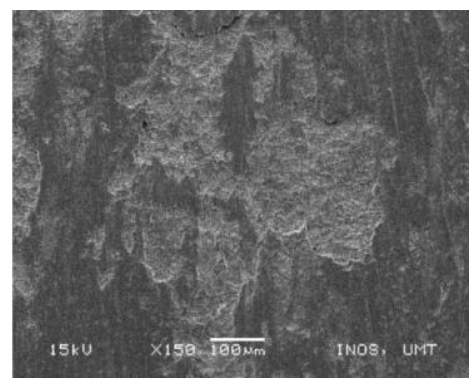

a)

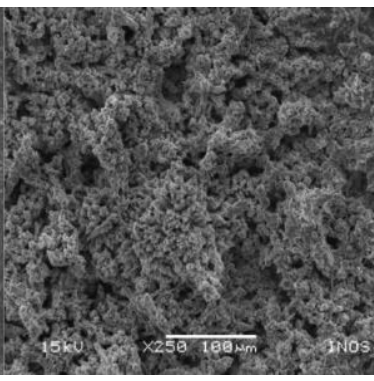

b)

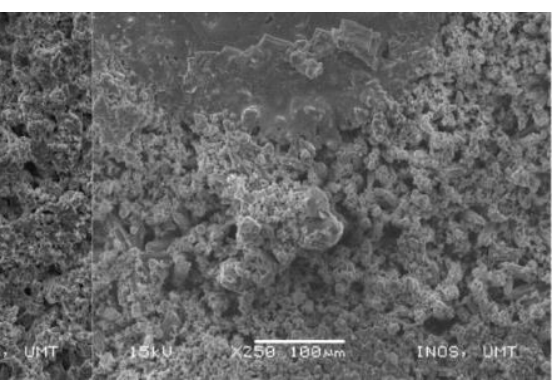

c)

Figure 6: SEM results for a) uncoated mild steel surface b) uncoated after 28 days for $0 \mathrm{~m} / \mathrm{s} \mathrm{c}$ ) uncoated after 7 days for $0 \mathrm{~m} / \mathrm{s}$

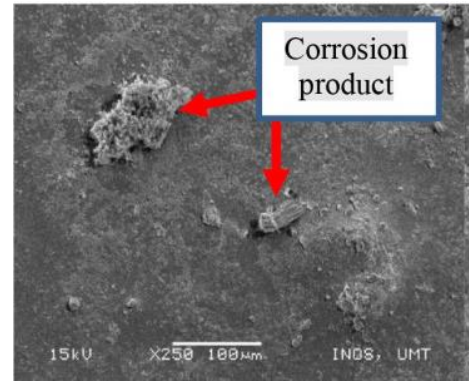

a)

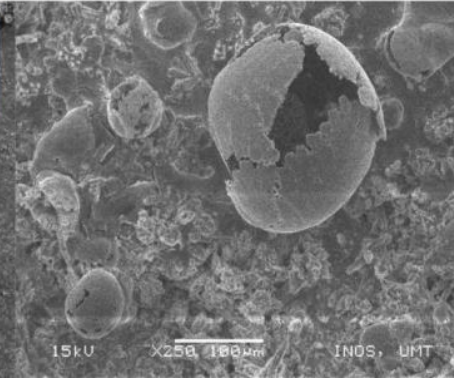

b)

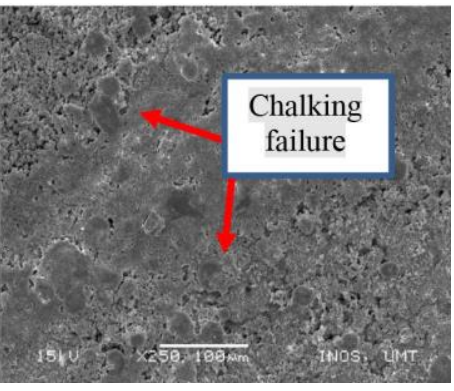

c)

Figure 7: SEM results for a) with additive after 7 days $0 \mathrm{~m} / \mathrm{s}$ b) uncoated for 28 days for $0.114 \mathrm{~m} / \mathrm{s} \mathrm{c}$ ) with additive after 28 days for $0.114 \mathrm{~m} / \mathrm{s}$

\section{Conclusion}

The efficiency of pigeon orchid to act as a green additive has been examined in this research. FTIR spectrum showed the constituent's functional group that actively acts as a corrosion inhibitor. Meanwhile, the efficiency of pigeon orchid to inhibit corrosion has been examined through EIS, SEM and optical microscope. The positive results from these three assessments have shown that pigeon orchid has the ability to impede corrosion activity when the performance against oxidation of $20 \%$ additive was better than with no additive added in the paint via Nyquist plot. Increasing velocity had caused reduced polarisation resistance, increased $\mathrm{I}_{\text {corr }}$, increased $\mathrm{E}_{\text {corr }}$ as well as increased corrosion rate and weight loss, hence reducing the thickness of the paint. The morphological visualisation from SEM and optical microscope supported the evidence. Thus, it can be concluded that pigeon orchid has the potential to be the new green additive since it is affordable, economical and environmentally friendly.

\section{Acknowledgements}

Authors would like to acknowledge Universiti Malaysia Terengganu for the facilities and support.

\section{References}

Abadias, G., Chason, E., Keckes, J., Sebastiani, M., Thompson, G. B., Barthel, E., ... \& Martinu, L. (2018). Stress in thin films and coatings: Current status, challenges, and prospects. Journal of Vacuum Science \& Technology A: Vacuum, Surfaces, and Films, 36(2), 020801.

Abdulla, M., Al-Agez, M., \& Fouda, A.S. (2009). Phenylhydrazone derivatives as corrosion inhibitors 
for- $\alpha$-brass in hydrochloric acid solutions. International Journal of Electrochemical Science, 4, 336-352.

Ahmad, A. (2014). Maritime power and strategy. National Defence University Journal, 23-42.

Alibakhshi, E., Ramezanzadeh, M., Bahlakeh, G., Ramezanzadeh, B., Mahdavian, M., \& Motamedi, M. (2018). Glycyrrhiza glabra leaves extract as a green corrosion inhibitor for mild steel in $1 \mathrm{M}$ hydrochloric acid solution: experimental, molecular dynamics, Monte Carlo and quantum mechanics study. Journal of molecular liquid, 255, 185-198.

Arockiasamy, P., Sheela, X., Thenmozhi, G., Franco, M., Sahayaraj, J. W., \& Santhi, R. J. (2014). Evaluation of corrosion inhibition of mild steel in $1 \mathrm{M}$ hydrochloric acid solution by Mollugo cerviana. International Journal of Corrosion, 2014.

Bakri, M. K. B., \& Jayamani, E. (2016). Comparative study of functional groups in natural fibers: Fourier transforms infrared analysis (FTIR). Futuristic Trends Engineering Science, Humanities and Technology, 16, 167.

De Baere, K., Verstraelen, H., Rigo, P., Van Passel, S., Lenaerts, S., \& Potters, G. (2013). Reducing the cost of ballast tank corrosion: an economic modelling approach. Marine Structures, 32, 136152.

Ebenso, E. E., Eddy, N. O., \& Odiongenyi, A. O. (2008). Corrosion inhibitive properties and adsorption behavior of ethanol extract of Piper guinensis as a green corrosion inhibitor for mild steel in H2SO4. African Journal of Pure and Applied Chemistry, 2(11), 107-115.

Fredj, N., Burleigh, T. D., Heidersbach, K. L., \& Crowder, B. R. (2012). Corrosion of carbon steel in waters of varying purity and velocity. In CORROSION 2012. National Association Corrosion Engineers International.

Ikhmal, W. M. K. W. M., Yasmin, M. Y. N., Fazira, M. F. M., Rafizah, W. A. W., Nik, W. W., \& Sabri, M. G. M. (2018, April). Anticorrosion Coating using Olea sp. Leaves Extract. In $I O P$ Conference Series: Materials Science and Engineering, 344(1), P012028. IOP Publishing.

Lebrini, M., Robert, F., Lecante, A., \& Roos, C. (2011). Corrosion inhibition of C38 steel in $1 \mathrm{M}$ hydrochloric acid medium by alkaloids extract from Oxandra asbeckii plant. Corrosion Science, 53(2), 687-695.

Li, Z., Zhang, J., \& Cheng, J. (2017). the influence of critical flow velocity on corrosion of stainless steel. Journal of Failure Analysis and Prevention, 17(6), 1234-1240.

Maria, M. F. F., Ikhmal, W. M. K. W. M., Amirah, M. N. N. S., Manja, S. M., Syaizwadi, S. M., Chan, K. S., ... \& Adnan, A. (2019). Green approach in anti-corrosion coating by using Andrographis paniculata leaves extract as additives of stainless steel $316 \mathrm{~L}$ in seawater. International Journal of Corrosion Scale Inhibitions, 8(3), 644 658.

Munger, C. G. (2014). Causes and Prevention of Paint Failure, Ponderosa Protective Coatings, pp. 1-21.

Niu, Q., Li, Z., Cui, G., \& Wang, B. (2017). Effect of flow rate on the corrosion behaviour of $\mathrm{N} 80$ steel in simulated oil field environment containing $\mathrm{CO}_{2}$ and HAc. International Journal of Electrochemical Science, 12(11), 10279-10290.

Ramezanzadeh, M., Sanaei, Z., Bahlakeh, G., \& Ramezanzadeh, B. (2018). Highly effective inhibition of mild steel corrosion in $3.5 \% \mathrm{NaCl}$ solution by green Nettle leaves 
extract and synergistic effect of ecofriendly cerium nitrate additive: Experimental, MD simulation, and QM investigations. Journal of Molecular Liquids, 256, 67-83.

Sandrasagaran, U. M., Subramaniam, S., \& Murugaiyah, V.(2014). New perspective of Dendrobium crumenatum orchid for antimicrobial activity against selected pathogenic bacteria. Pakistan Journal of Botany, 46(2), 719-24.

Satapathy, A. K., Gunasekaran, G., Sahoo, S. C., Amit, K., \& Rodrigues, P. V. (2009). Corrosion inhibition by Justicia gendarussa plant extract in hydrochloric acid solution. Corrosion science, 51(12), 2848-2856.

Verma, C., Ebenso, E. E., Bahadur, I., \& Quraishi, M. A. (2018). An overview of plant extracts as environmentally sustainable and green corrosion inhibitors for metals and alloys in aggressively corrosive media. Journal of Molecular Liquids, 266, 577-590.

Yan, L., Wang, X., Liu, H., Tian, Y., Lian, J., Yang, R. \& Qi, S. (2015). The genome of Dendrobium officinale illuminates the biology of the important traditional Chinese orchid herb. Molecular plant, 8(6), 922-934. 